\begin{tabular}{c|l|l|l}
$\begin{array}{c}\text { Case Reports in } \\
\text { Oncology }\end{array}$ & $\begin{array}{l}\text { Case Rep Oncol 2011;4:35-38 } \\
\text { DOl: 10.1159/000324182 }\end{array}$ & $\begin{array}{l}\text { Published online: } \\
\text { January 25, 2011 }\end{array}$ & $\begin{array}{l}\text { O 2011 S. Karger AG, Basel } \\
\text { ISSN 1662-6575 } \\
\text { www.karger.com/cro }\end{array}$ \\
\hline
\end{tabular}

\title{
Facial Nerve Palsy: An Unusual Presenting Feature of Small Cell Lung Cancer
}

\author{
Ozcan Yildiz ${ }^{\mathrm{a}}$ Deram Buyuktas ${ }^{\mathrm{a}}$ Esra Ekiz $^{\mathrm{c}}$ \\ Fatih Selcukbiricik $^{a}$ Irfan Papilab Cigdem Papila ${ }^{a}$ \\ aDepartment of Internal Medicine, Division of Medical Oncology, and \\ ${ }^{b}$ Department of Head and Neck Surgery, Cerrahpasa Medical Faculty, Istanbul \\ University, and 'Department of Internal Medicine, Goztepe Education and \\ Research Hospital, Istanbul, Turkey
}

\section{Key Words}

Facial nerve paralysis · Facial nerve metastasis $\cdot$ Small cell lung cancer

\begin{abstract}
Lung cancer is the second most common type of cancer in the world and is the most common cause of cancer-related death in men and women; it is responsible for 1.3 million deaths annually worldwide. It can metastasize to any organ. The most common site of metastasis in the head and neck region is the brain; however, it can also metastasize to the oral cavity, gingiva, tongue, parotid gland and lymph nodes. This article reports a case of small cell lung cancer presenting with metastasis to the facial nerve.
\end{abstract}

\section{Introduction}

Despite being a rare disease in the early 20th century, lung cancer has since become of great clinical importance due to the increasing number of cases each year and the high death rates in spite of the improvements related to its treatment. Bronchogenic carcinoma is one of the most common types of cancer with a propensity to metastasize to the brain in the head and neck region; it may cause headache, vertigo, hemiparesis, convulsions, difficulty in speech and blurred vision. Our case represents the second case in the existing literature with a diagnosis of facial nerve paralysis due to small cell lung cancer metastasis.

\section{Case Report}

A 50-year-old male was admitted to the ear, nose and throat (ENT) outpatient clinic with a 4-day history of numbness in the left half of his face. He also stated that he had experienced weight loss and dysphonia for 2 months. On physical examination, he had a left cervical lymphadenomegaly with moderate consistency measuring $2 \times 2 \mathrm{~cm}$; the rest of the ENT examination was normal. He was 
diagnosed with acute left peripheral facial paralysis. Laryngeal endoscopy revealed left vocal cord paralysis. The patient was put on corticosteroids and sent for cervical magnetic resonance imaging (MRI), which revealed multiple lymphadenopathies on the left spinal, left internal jugular and right posterior deep cervical axes and the left supraclavicular region. Incisional biopsy of the left cervical lymph node revealed small cell bronchogenic carcinoma metastasis. The patient then had computed tomography (CT) of the thorax and a cranial MRI which showed an expansile lesion measuring $6 \mathrm{~cm}$ at its longest diameter in the left upper lung and leptomeningeal metastasis inside the left internal auditory canal accompanied by contrast enhancement on the left facial nerve (fig. 1). Cranial MRI also detected metastases in the hypophysis, hypothalamus, cerebellum and right parietal bone. Subsequently, the patient was referred to the medical oncology department, where he had an abdominal CT which revealed metastatic lesions in the liver, junction of the pancreatic head and neck, left adrenal gland and lymphadenomegalies in the interaortocaval, retrocaval and left paraaortic regions. Total body bone scintigraphy showed metastases in the calvarium and costae. Thorax CT was repeated and showed a mass measuring $8 \times 8.5 \times 10.5 \mathrm{~cm}$ in diameter, obliterating the left main pulmonary artery and left main bronchus at the left hilum. In light of all these findings, the patient was diagnosed with metastatic small cell lung cancer and along with intravenous corticosteroids, cranial radiotherapy (RT) was started. Facial paralysis regressed after RT, and once the RT sessions were over, he was put on chemotherapy with cisplatin $75 \mathrm{mg} / \mathrm{m}^{2}$ and etoposide $100 \mathrm{mg} / \mathrm{m}^{2}$. However, the patient died 4 months after diagnosis, following the third cycle of chemotherapy.

\section{Discussion}

Acute peripheral facial paralysis is a common entity, and a number of possible causes can be encountered upon reviewing the literature. Bell's palsy, an acute isolated peripheral facial nerve paralysis without any particular cause, is the most common cause of peripheral facial paralysis [1]. Infections (acute and chronic otitis media, Lyme disease, HIV, EBV, CMV, herpes viruses and rickettsiae, measles, mumps and Ramsey-Hunt syndrome, which is an inflammatory condition related to VZV infection), trauma (external or iatrogenic), neoplasia (acoustic neurinoma, glomus jugulare, glomus caroticum and parotid gland tumors), tumors of the parathyroid gland, metastases from head and neck carcinomas such as nasopharynx cancer, congenital disorders (Moebius syndrome) and autoimmune diseases (sarcoidosis, Guillain-Barre syndrome) can cause facial paralysis.

May and Schaitkin [1] could not find any etiologic factor in $51 \%$ of 3,650 patients with peripheral facial nerve paralysis they followed up between 1963 and 1996. A much more significant point is that there is a possibility of a life-threatening condition in some of the Bell's palsy patients: they found an etiologic factor in 300 (13\%) of 2,256 patients referred to their clinic with a diagnosis of Bell's palsy, in whom neoplasms, herpes zoster cephalicus and other infections were the leading causes.

Metastasis to the temporal bone is a rare condition. The most common metastasizing malignancies are of the breast, lung, kidney, gastrointestinal tract, prostate and thyroid. They spread via a hematogenous route and might present with hypoacusis, tinnitus, dizziness, vertigo and peripheral facial nerve palsy $[2,3]$.

Lung cancer commonly metastasizes to the central nervous system, bone, liver and adrenal glands. Small cell lung cancer comprises $15 \%$ of all bronchogenic carcinomas and has a potential to metastasize early in the course of the disease [4]. The most common site of head and neck metastasis of lung cancer is the brain, but it can also spread to the oral cavity, gingiva, tongue, parotid gland and lymph nodes [5]. On reviewing the literature, one can come across parotid gland metastases of small cell lung cancer without invasion 
of the facial nerve [6]. On the other hand, there are a few reported cases of nonbronchogenic malignant tumors, such as lymphoma, metastasizing to the facial nerve [7].

There are several cases of lung cancer presenting with facial paralysis in the English literature [8-10]. Most of these cases were adenocarcinoma, 2 of them were squamous cell carcinoma, 1 of them was small cell carcinoma and in 1 of them, cellular type was not reported. With only 1 exception, there were metastases in the internal acoustic canal in all cases.

Bergstrom et al. [8] presented a patient with bilateral deafness and facial paralysis who was diagnosed with bronchogenic carcinoma with metastases to the dura mater, brain stem, pons, cerebellopontine angle and the $3 \mathrm{rd}, 6 \mathrm{th}, 7 \mathrm{th}$ and 8 th cranial nerves. The tumor caused bilateral corrosion on the internal acoustic meatus and invaded the right facial, acoustic and glossopharyngeal nerves. The patient died 2 months after diagnosis.

Another case presenting with left facial paralysis was reported by Teschner et al. [9]. The reason for the paralysis was initially thought to be an infection, and both corticosteroids and antibiotics were started. Though the paralysis did not cease, the patient was discharged. Later, the same patient presented with a mass on his neck and radiologic imaging revealed bilateral internal jugular venous thrombosis. Meanwhile, thorax CT as well as the diagnostic extirpation of an enlarged cervical lymph node led to the diagnosis of a metastasized small cell neuroendocrine bronchogenic carcinoma with compression of the right primary bronchus and the superior vena cava, as well as an upper inflow congestion. Cranial MRI showed a metastasis in the area of the foramen stylomastoideum, and axial images showed the tumor being adjacent to the facial nerve, which explained the facial paralysis. The patient underwent emergency radiation and chemotherapy with cisplatin and etoposide; however, he died 2 months later.

Schrock et al. [10] presented a patient with dizziness, deafness and right facial paralysis in whom cranial MRI detected a mass on the right internal acoustic meatus, leading both radiologically and clinically to an initial diagnosis of vestibular schwannoma; biopsy from that mass revealed squamous cell carcinoma. Bronchoscopy was performed, which showed a mass lesion in the lung. After excision of the mass, the patient was started on carboplatin and gemcitabine, which were given for 4 cycles. Months later, metastases to the cerebellum and brainstem were detected and the patient died.

In our case, small cell lung cancer metastasized to several intracranial regions and the geniculate ganglion of the left facial nerve. Compared to other previous publications of cases involving both small cell lung cancer and presenting with facial nerve paralysis without hearing loss, this is the second case report with direct facial nerve involvement. Our patient was started on intravenous corticosteroid therapy in addition to cranial RT and continued with a chemotherapy regimen consisting of cisplatin and etoposide. Four months later, the patient died after receiving the third course of chemotherapy.

\section{Conclusion}

Although Bell's palsy is the most common cause of peripheral facial nerve paralysis, metastatic conditions should be recalled in cases such as ours who present with facial nerve paralysis but do not recover with appropriate treatment. 


\begin{tabular}{c|l|l|l}
$\begin{array}{c}\text { Case Reports in } \\
\text { Oncology }\end{array}$ & $\begin{array}{l}\text { Case Rep Oncol 2011;4:35-38 } \\
\text { DOl: 10.1159/000324182 }\end{array}$ & $\begin{array}{l}\text { Published online: } \\
\text { January 25, 2011 }\end{array}$ & $\begin{array}{l}\text { O 2011 S. Karger AG, Basel } \\
\text { ISSN 1662-6575 } \\
\text { www.karger.com/cro }\end{array}$ \\
\hline
\end{tabular}

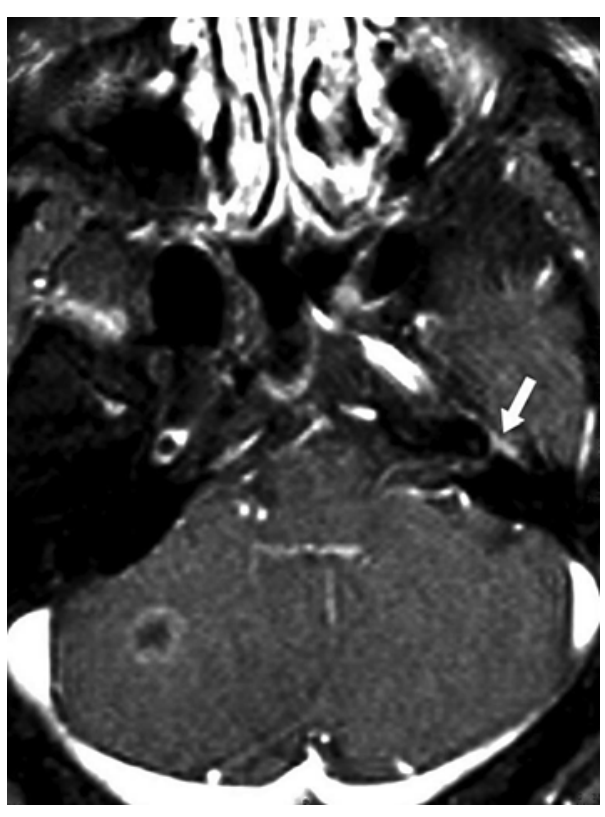

Fig. 1. Metastasis inside the left internal auditory canal accompanied by contrast enhancement on the left facial nerve (arrow).

\section{References}

1 May M, Schaitkin BM: The facial nerve; in Schaitkin BM, May M, Klein SR (eds): Office Evaluation of the Patient with Facial Palsy: Differential Diagnosis and Prognosis. 2nd ed. New York, Thieme Medical Publishers, 2000, pp 179-212.

2 Lan MY, Shiao AS, Li WY: Facial paralysis caused by metastasis of breast carcinoma to the temporal bone. J Chin Med Assoc 2004;67:587-590.

-3 Miro Castillo N, Roca-Ribas Serda F, Barnadas Molins A, Prades Marti J, Casamitjana Claramunt F, Perello Scherdel E: Facial paralysis of metastatic origin. Review of metastatic lesions of the temporal bone (in Spanish). An Otorinolaringol Ibero Am 2000;27:255-263.

4 Sher T, Dy GK, Adjei AA: Small cell lung cancer. Mayo Clinic Proc 2008;83:355-367.

-5 Hirshberg A, Buchner A: Metastatic tumors to oral region. An overview. Eur J Cancer B Oral Oncol 1995;31B: $355-360$.

6 Boeger D, Hocke T, Esser D: The interesting case - case no. 68. Metastasis of small cell bronchial carcinoma to the parotid gland. Laryngorhinootologie 2005;84:117-120.

7 Palva T, Palva A, Dammert K, Karma P: Malignant lymphoma invading the facial nerve. Arch Otolaryngol 1974;99:433-436.

8 Bergstrom LV, Baker BB, Sando I: Sudden deafness and facial palsy from metastatic bronchogenic carcinoma. J Laryngol Otol 1977;91:787-793.

-9 Teschner M, Durisin M, Mangold A, et al: Peripheral facial palsy as the first symptom of a metastatic bronchogenic carcinoma. Laryngorhinootologie 2006;85:512-516.

10 Schrock A, Laffers W, Bootz F: Solitary metastasis of lung carcinoma to the internal auditory canal. Am J Otolaryngol 2006;27:214-216. 